\title{
Go Green and Save Green: A Detailed Study about Green Computing
}

\author{
R. Bakkiylakshmi ${ }^{1}$, T. Jenifer ${ }^{1}$, Gayathri Premananad \\ Assistant Professor, Department of Computer Science, Sri Saradha College for Women, Perambalur, India ${ }^{1}$
}

\begin{abstract}
Today ICT era, computer plays a vital role in all organizations. Most of the organization makes computers as compulsory for all because using computing resources to perform a multitude of tasks, including work, research, teaching and learning. As computer system increasing so the amount of energy conservation and the carbon contents are increasing in atmosphere. Measure being taken to reduce the problem superficially called "green computing". So the IT department uses the most of power which in turn is an excessive amount of overhead for a business as well as a source for toxic waste. Making IT "Green" can not only save money but help save our world by making it a better place through reducing and/or eliminating wasteful practices and using nontoxic materials. This study is briefly explain about Green which include what is Green Computing, Why Green Computing, How to make IT into Green and their approaches, and the implementation of Green computing.
\end{abstract}

Keywords: Green IT, Green Computing, Recycling, Virtualization

\section{INTRODUCTION}

Computers today not only used in offices but also at homes. As the number of computers is increasing day by day, so is the amount of electricity consumed by them which in turn is increasing the carbon content in atmosphere. This problem has been realized by people and measures are being taken which help in minimizing the power usage of computers. Therefore, this can be called as Green Computing. Green computing is the environmentally responsible and ecofriendly use of computers and their resources. In broader terms, it is also defined as the study of designing, engineering, manufacturing, using and disposing of computing devices in a way that reduces their environmental impact. Green computing is also known as green information technology (green IT). Many IT organizations are looking at Green IT programs to achieve objectives that include improving energy efficiency and power management practices, increasing hardware utilization, reducing life-cycle costs and looking for ways to cut down on computer waste. ${ }^{[2]}$ The major areas of activity associated with these programs fall generally into the following categories

- $\quad$ Energy consumption

- $\quad$ Power consumption

- $\quad$ Cooling

- $\quad$ Green procurement and asset management

- $\quad$ Technology based solution

There are a lot of fundamental steps that can be taken to significantly decrease the power consumption and impact on environment. ${ }^{[3]}$ Some of them are

- Lower Power hardware - Computer systems are made up of hardware i.e. processor onboard graphics, disk, fan etc these hardware should be consumed less power.

- Virtualization - It is the use of software to simulate hardware. In the data center stand alone server system replaced with virtual server that run as software on a small number of larger computer via a virtualized server we can efficiently use computer resources.

- $\quad$ Cloud computing - It enables anybody can obtain environmental benefits of virtualization. It also remove the need for the user to run high power PCs since it provide infrastructure as a service.

- Wireless Network Sensor - Sensor employed in different parts area in a data center to determine the temperature of each area, this will tell which area need to be more cool and where to reduce cooling.

- $\quad$ Recycle - Through recycling the waste or equipment we can reduce the environmental pollution.

\section{GREEN COMPUTING - WHY?}

In today's business world, the transaction is done almost $24 / 7$ across all the available channels and they must collect, store, track and analysis enormous amount of data from many servers that can be scattered across the world. But this all comes with a cost to both businesses and the environment. Data warehouses and the sprawling data centers that house 


\section{International Journal of Advanced Research in Computer and Communication Engineering}

Vol. 8, Issue 1, January 2019

them use up a huge amount of power, both to run legions of servers and to cool them. Just how much? A whopping 61 billion kilowatt-hours of electricity, at an estimated cost of $\$ 4.5 \mathrm{~B}$ annually.

On one side of the industries has achieved more comfort and efficiency but on the other side added CFC's i.e. Chloro Fluro compounds and Carbons and $\mathrm{CO}_{2}$ to cause Global warming. Global warming and the problem of minimizing environmental impact from fossil-fuel emissions have raised to the top of global public policy agenda. As a result, businesses and consumers alike have started to embrace environmentally sustainable products that offer low-carbon solutions that can not only reduce their global greenhouse gas (GHG) emissions, but can do so by more efficient energy consumption and lower costs. The balanced growth with respect to social and environmental point of view will be the solution to enjoy long and healthy life. This can be done by using machines with simple care such as

- $\quad$ Using Auto Stop soft ware to shut off machines when they are idle for long.

- $\quad$ Using biodegradable materials.

- $\quad$ Proper management like putting off the systems before leaving work place for the day

- Recycling and donating computers of previous generations to less fortunate as social responsibility to maximum use.etc will help us to maintain the balance in NEED and WANTS or GREED.

So, the major role of Green Computing is the environmentally responsible use of computers and related resources. Such practices include the implementation of energy-efficient central processing units (CPUs), Servers and Peripherals as well as reduced resource consumption and proper disposal of electronic waste (e-waste). Green computing is the study and practice of efficient and eco-friendly computing (+ communication). Green computing is a very emerging topic these days, not only because of rising energy costs and potential savings, but also due to the impact on the environment. Energy to manufacture, store, operate, and cool computing systems has grown significantly in the recent years, primarily due to the volume of systems and computing that companies now heavily rely upon.

\section{APPROACHES TOWARDS GREEN COMPUTING}

Green computing represents environmentally responsible way to reduce power and environmental e-waste. Virtualization, Green Data Center, Cloud computing, grid computing, Power optimization are the technologies of green computing. Main goals of green computing are to reduce the use of toxic and hazards materials and improve the energy efficiency, recycling of factory waste. Such practice includes the efficient implementation of server and peripherals as well as reduces the power consumption.

Other than the major technologies some of the techniques are listed here to accomplish Green from individuals. They are

- $\quad$ Terminal servers - When using the system, users at a terminal connect to a central server; all of the actual computing is done on the server, but the end user experiences the operating system on the terminal.

- $\quad$ Power management - This allows a system to automatically turn off components such as monitors and hard drives after set periods of inactivity. In addition, a system may hibernate, where most components (including the CPU and the system RAM) are turned off.

- Avoid Screensavers - Never believe that screen-savers can save power or can keep your monitors in good health. They originally consume more power than monitors that are allowed to get dimmed out when not working.

- $\quad$ Display - CRT monitors typically use more power than LCD monitors. They also contain significant amounts of lead. LCD monitors typically use a cold-cathode fluorescent bulb to provide light for the display. Some newer displays use an array of light-emitting diodes (LEDs) in place of the fluorescent bulb, which reduces the amount of electricity used by the display. Fluorescent back-lights also contain mercury, whereas LED back-lights do not.

- Materials recycling - Recycling computing equipment can keep harmful materials such as lead, mercury, and hexavalent chromium out of landfills, and can also replace equipment that otherwise would need to be manufactured, saving further energy and emissions. Computer systems that have outlived their particular function can be re-purposed, or donated to various charities and nonprofit organizations. The recycling of old computers raises an important privacy issue.

- $\quad$ Product longevity - Before buying a new PC think if upgrade of the old one is possible. For instance, manufacturing a new PC makes a far bigger ecological footprint than manufacturing a new RAM module to upgrade an existing one, a common upgrade that saves the user having to purchase a new computer.

- $\quad$ Video card - A fast GPU may be the largest power consumer in a computer. Energy-efficient display options include: No video card - use a shared terminal, shared thin client, or desktop sharing software if display required. Use motherboard video output - typically low 3D performance and low power. Select a GPU based on low idle power, average wattage, or performance per watt.

- Telecommuting - Teleconferencing and telepresence technologies are often implemented in green computing initiatives. The advantages are many; increased worker satisfaction, reduction of greenhouse gas emissions related to travel, and increased profit margins as a result of lower overhead costs for office space, heat, lighting, etc.

As IT users, we can also contribute our own effort to protect the environment by operating the IT equipment wisely. We have collected the following information from various sources for our reference: 


\title{
International Journal of Advanced Research in Computer and Communication Engineering
}

\author{
Vol. 8, Issue 1, January 2019
}

1) Do not leave your computer running overnight and on weekends. A modest amount of turning on and off will not harm the computer or monitor. The life of a monitor is related to the amount of time it is in use, not the number of on and off cycles.

2) Do not turn on the printer until you are ready to print. Printers consume energy even while they are idling. Do not print out copies of email unless necessary.

3) If you spend a large amount of time at your computer, consider reducing the light level in your office. This may improve CRT (cathode ray tube) screen visibility as well as save energy.

4) Most computer equipment now comes with power management features. If your computer has these features, make sure they are activated.

5) Use "paperless" methods of communication such as email and fax-modems.

6) When typing documents, especially drafts, use a smaller font and decrease the spacing between lines, or reformat to keep your document to as few pages as possible, especially when typing drafts.

7) Review your document on the screen instead of printing a draft. If you must print a draft, use the blank back side of used paper.

8) Use a printer that can print double-sided documents. When making copies, use double-sided copying.

9) Always buy and use recycled-content paper. Look for papers with $50-100 \%$ post-consumer waste and nonchlorine bleached. Also, recycle your paper when done.

10) Buy a monitor only as large as you really need. Although a large monitor might seem more attractive, you should remember that a 17 -inch monitor uses 40 percent more energy than a 14 -inch monitor. Also, the higher the resolution, the more energy it needs.

11) Ink-jet printers, though a little slower than laser printers, use 80 to 90 percent less energy.

12) Request recycled / recyclable packaging from your computer vendor.

13) Buy vegetable (or non-petroleum-based) inks. These printer inks are made from renewable resources; require fewer hazardous solvents; and in many cases produce brighter, cleaner colors.

\section{CONCLUSION}

This paper is survey or a brief study about a green computing. The study will also tell the approaches of green computing. What and how much work done in green computing and how the power consumption is reduced through different approaches and key challenges facing to accomplish the goal. The concept of green computing is popularized in the past few years. Apart from ecological issues, this also deals in economic needs. This paper aimed to provide a survey on the current state-of-the-art in green computing. In addition, details of some real solutions have been showed as well.

"We are not passive spectators, but active contestants in the drama of our existence.

We need to take responsibility for the kind of life we create for ourselves"

- Nathaniel Branden, Ph.D.

So it is our responsibility to save the environment.

Go Green and Save Green!

\section{ACKNOWLEDGEMENT}

Any achievement, be it scholastic or otherwise does not depend solely on the individual efforts but on the guidance, encouragement and cooperation of intellectuals, elders and friends. A number of personalities, in their own capacities have helped us in carrying out this paper work. We would like to take this opportunity to thank them all. We conveying our sincere thanks towards the following Papers are help us while preparing this paper. Last, but not the least, I would like to thank my peers and friends who provided me with valuable suggestions to improve my paper.

\section{REFERENCES}

[1]. Dr. M. S. Kadam and Prof. Dharmendra Singh, “Approaches to Green Computing to Reduce Global Warming”, IBMRD's Journal of Management and Research, pp. 413-4240, March 2013

[2]. Miss Swati Aggarwal, Mrs.Monika Garg, Mr. Pramod Kumar, "Green Computing is a SMART COMPUTING - A Survey", International Journal of Emerging Technology and Advanced Engineering, pp. 297- 303, February 2012.

[3]. Pushtikant Malviya, Shailendra Singh, “A Study about Green Computing”, International Journal of Advanced Research in Computer Science and Software Engineering, pp. 790-794, June 2013.

[4]. Prof. Riyaz A. Sheikh, Dr. U.A. Lanjewar, "Green Computing- Embrace a Secure Future", International Journal of Computer Applications, pp. 22-26, November 2010.

[5]. Mrs .Sharmila Shinde, Mrs. Simantini Nalawade, Mr .Ajay Nalawade, "Green Computing: Go Green and Save Energy", International Journal of Advanced Research in Computer Science and Software Engineering, pp.1033-1037, July 2013. 


\section{IJARCCE}

Vol. 8, Issue 1, January 2019

\section{BIOGRAPHIES}

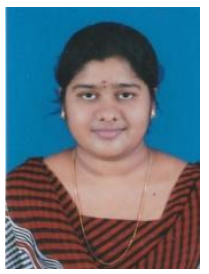

Bakkiyalakshmi was born in 1994. Now she is working as a Assistant Professor in Department of Computer Science Sri Saradha College for Women, Perambalur. She Complete her research (M.Phil), Department of computer science, Applications and Information technology in Shrimati Indira Gandhi College, Trichy. She obtained B.Sc and M.Sc(Computer Science) degree in 2014 and 2016 respectively, from Seethalakshmi Ramasami College, Trichy. She is an avid coder who always looks to develop something new. Now she is looking forward to improve her skill in software developing. Her areas of working interest are Network Security, Data Mining and Data Structures.

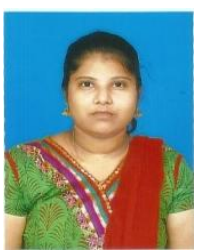

Jenifer was born in 1990, now she is working as a Assistant Professor in Department of Computer Science Sri Saradha College for Women, Perambalur. She has done her M.Phil at Department of computer science, Applications and Information technology in Shrimati Indira Gandhi College, Trichy. She finished her Masters in Computer Application from M.A.M Engineering College, Trichy in 2013. She has done Bachelor Degree of Computer Science from Shrimati Indira Gandhi College, Trichy in 2010. She has worked as a teacher at CSC Computer Education Center and worked as a Software Developer at Techlife Global. Her current research interests include Data Mining and Network Security.

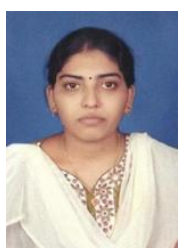

Gayathri Premanand was born in 1993. She completed her Master of Philosophy in Computer Science from Department of computer science, Applications and Information technology in Shrimati Indira Gandhi College, Trichy. She has completed her MCA in Cauvery College for Women, Trichy during 2015 and she completed her Bachelor Degree in Computer Science at the same college during 2013. She loves to work on Software related problems. Her research interests cover Network Security and Computer Graphics. 